DOI 10.37882/2500-3682.2021.03.06

\title{
ПОНЯТИЕ «МЕНТАЛИТЕТ» КАК КУЛЬТУРОЛОГИЧЕСКАЯ КАТЕГОРИЯ
}

\section{THE CONCEPT OF "MENTALITY" AS A CULTURAL CATEGORY}

\section{Kovaleva}

Summary: The article is devoted to the history of the origin and formation of the term "mentality". The article considers the process of searching for the necessary definitions in science to develop common approaches to understanding the mentality; provides an idea of the contribution of Western European and Russian, as well as Soviet scientists to the development of the concept of "mentality"; determines the dependence of the definition of the concept of "mentality" on the nature of research tasks and the social position of the researcher.

Keywords: mentality, periods of scientific formation of the term, cultural and social diversity of peoples, search for definitions, scientific category.
Ковалёва Инна Алексеевна

Аспирант, Российский государственный социальный университет (Москва)

in_kov19@mail.ru

Аннотация: Статья посвящена истории происхождения и становления термина «менталитет». В статье рассматривается процесс поиска необходимых дефиниций в науке для выработки общих подходов в понимании менталитета; дается представление о вкладе в развитие понятия «менталитет» научных исследований западноевропейских и русских, а также советских учены; определяется зависимость определения понятия «менталитет» от характера исследовательских задач и социальной позиции исследователя.

Ключевые слова: менталитет, периоды научного становления термина, культурное и социальное многообразие народов, поиск дефиниций, научная категория.

\section{ВвеАение}

$\mathrm{O}$ дним из самых неоднозначных в современной культурологической науке является понятие «менталитет», который в то же время все более активно используется исследователями культуры. Это понятие имеет свою историю происхождения, которую условно можно разделить на два этапа. Первый этап заключается в постепенном расширении знаний о культурных феноменах, которые позже были названы «менталитетом», но вызывали повышенный интерес ученых, изучающих культуры различных народов и этносов. Так, выяснилось, что за внешними описаниями той или иной культурной общности, остается нечто, что недоступно внешнему наблюдателю, но существенно определяет внутреннее содержание изучаемой культуры. Второй этап изучения менталитета связан с попытками его осмысления в научно-понятийном аспекте в начале $\mathrm{XX}$ века. В отечественной культурологии понятие «менталитет» начинает использоваться в 90-х годах XX века.

Само понятие «менталитет» в его буквальном значении ведет свое происхождение от латинского слова «mens», что означает «разум», «мышление». Если ограничиться таким зауженным пониманием менталитета, то тогда останутся в стороне те его характеристики, которые не сводятся к рациональному познанию мира, но представляют собой сложный комплекс эмоционально-чувственных восприятий, образных представлений, верований и т.д., которые «не схватываются» в рамках привычного понятийно-категориального подхода. В результате сложилась в исследованиях менталитета до- вольно двусмысленная ситуация - явление менталитета, ментальности признается многими учеными как объективно существующее, но одновременно оно не представлено в системе онтологических представлений о той или иной культуре как научный факт.

Несмотря на это, уже в 17 веке термин «менталитет» начинает использоваться, обретая в то же время самое широкое толкование. В конце 19 века интерес к явлениям, в изучении которых используется этот термин пока в нестрогом его значении, связан преимущественно с исследованием примитивных обществ и культур. Параллельно шел процесс поиска необходимых дефиниций в науке для выработки общих подходов в понимании менталитета, который вначале интенсивно изучается социологами и антропологами, затем - психологам, историками и лингвистами.

Вместе с тем, нельзя не отметить, что до настоящего времени в научном сообществе культурологов так и не сложилось единого представления об этом культурном феномене, как и соответствующей системы его теоретического описания в системе научных понятий.

\section{Методика}

\section{Научно-описательный периох}

Для рассмотрения содержания понятия «менталитет» в культурологической науке уместен историко-генетический подход в его становлении и интерпретации. Так, уже в исторических изысканиях Геродота представ- 
лен разнообразный материал о традициях, обычаях, верованиях таких народов как персы, скифы, египтяне, ассирийцы [2]. Этот материал носил преимущественно описательный характер и имел эту особенность и в исследованиях средневековых ученых.

Собственно научное изучение менталитета начинается в Новое время. Это выразилось в том, что явления и факты, позже получившие название «менталитет» подверглись систематизации, обобщениям и основывались на целенаправленных наблюдениях за жизнью различных народов и этносов, не связанных непосредственно с материально-бытовой культурой, но представленные в духовной сфере: в обычаях, ритуалах, традициях, морали, верованиях и т.д.

Первым таким ученым, исследующим в первую очередь, политическую культуру различных стран и народов, стал Ш. Монтескье, обративший внимание современников на существование «духа народа», составляющего его культурное и социальное своеобразие. Причем эта особенность народов и этносов определяется, по его мнению, целой совокупностью факторов: климатом, традициями, религией, законами, особенностями правления, нравами [11]. Появление же этих факторов связано с физическими, социальными и моральными предпосылками.

Дэвид Юм уже обращал внимание исследователей на такую сторону менталитета как коллективность, которая, по его мнению, является проявлением нужд экономики, обороны, управления и соответственно в значительной мере носит принудительный характер.

Представление о «духе народов» развивал выдающийся просветитель-гуманист Иоганн Гердер, называя его «генетическим духом» или «характером народа». В качестве факторов их становления он выделял климатические особенности, природные условия, семейные отношения, при этом делая оговорку, что наглядно представить «народный дух» достаточно сложно.

Важным этапом в изучении менталитета стали исследования Мориса Лацаруса и Хеймана Штейнталя, создавшими научное направление - этническую психологию. В научный оборот вошло понятие «народный дух», которое уже использовал в своих трудах Гегель. Свой вклад в изучение менталитета как особого культурного феномена внесли Ральф Эмерсон и Эмиль Дюркгейм.

Понятие «менталитет» в качестве научной категории ввел в научный оборот Л. Леви-Брюль, изучая примитивные культуры и древние общества. В своих исследованиях ученый пришел к выводу о том, что все народы, этносы, так или иначе имеют собственные верования, которые и определяют в значительной мере их менталитет.
В вышедшей в 1925 году монографии Г. Бутуля «Менталитет» впервые было дано его развернутое определение. Менталитет им определялся как «совокупность идей и интеллектуальных установок, присущих индивиду и соединенных друг с другом логическими связями или же отношениями веры... Наш менталитет находится между нами и миром, как призма. Она, пользуясь выражением Канта, является априорной формой нашего познания»[4].

\section{Период школы «Анналов»}

Французская историографическая школа «Анналов» (основоположники - Л. Февр и М. Блок) по праву занимает лидирующее положение в истории изучения менталитета как феномена культуры.

М. Блок и Л. Февр при изучении менталитета обращали внимание на его продолжительность и связь с психологией носителей тех или иных ментальных состояний. Л. Февром, кроме того, было предложено понятие «ментальный инструментарий», который определялся им как «совокупность категорий восприятия, концептуализации, выражения и действия, которые структурируют опыт - как индивидуальный, так и коллективный».

Следующий представитель «Школы анналов» Ж. Ле Гофф расширил представления о ментальности, которые ранее сводили последнюю к определенным стереотипам мыслительной деятельности, иррациональным образам той или иной социальной и культурной группы, присущие исторической эпохе. С менталитетом этот исследователь связывал в первую очередь саму способность ориентироваться в окружающей действительности, причем реализуемой на уровне автоматизма.

Еще один исследователь, представлявший школу «Анналов», Ф. Бродель рассматривал феномен менталитета с учетом экономических и географических факторов. По его мнению, при изучении менталитета необходимо выделять два уровня жизнедеятельности любого общества: материальную и нематериальную. Последняя включает в себя психологию и культуру повседневности, которая и формирует мир ценностей и религиозную символику, составляющие основное содержание менталитета той или иной социальной группы и общности. Эти составляющие менталитета определяют в свою очередь семиотические структуры, картины мира в различных ее проявлениях, что и необходимо исследовать в первую очередь при изучении чьего-либо менталитета.

Известный исследователь массовой психологии Г. Лебон в изучении менталитета разных народов предлагал учитывать в первую очередь такие его составляющие как мир общих чувств, интересов и верований.

Если суммировать основные результаты изучения 
французскими исследователями понятия «менталитет», то можно сделать вывод, что это понятие они связывали в основном со сферой бессознательного и обобщенными картинами мира, сложившимися в сознании того или иного народа.

Важный вклад в изучение менталитета внес Э.Кассирер, который рассматривал это понятие в контексте символических форм культуры, особенности которых и определяют соответствующую ментальность того или иного народа.

Особо следует выделить исследования ментальных структур человечества, осуществленные К.Г. Юнгом, создавшим теорию «коллективного бессознательного» с его достаточно универсальными для различных культур и народов «архетипами». Архетипические структуры различных культур изучал и О. Шпенглер. Другой известный ученый Й. Хейзинга, разрабатывая теоретические аспекты ментальностей, расширил их значение как ключа к пониманию всей человеческой истории. Наконец, Э. Фромм предложил отождествлять понятие «менталитет» с «социальным характером».

Таким образом, в истории изучения понятия «менталитет», осуществляемого европейскими учеными выделяются такие его сущностные характеристики как психологические особенности того или иного народа, а также отображение реальности в соответствующих «картинах мира», формирующих соответствующие реакции на окружающую социальную действительность.

\section{Результаты}

Рассмотренные выше подходы к изучению понятия «менталитет» позволили исследовать становление и содержание этого понятия в отечественной науке. Выяснилось, что трактовка уже ставшего категорией культурологи менталитета в европейской науке не может быть интерпретирована однозначно в русском языке, где отсутствует близкое к нему понятие и его определение. Среди наиболее часто встречаемых частичных аналогов понятия «менталитет» можно выделить концепт «национальный характер», с которым многие российские ученые связывают наиболее существенные характеристики духовного облика народов России.

Тема «национального характера» являлась одной из излюбленных в трудах русских ученых, так или иначе, изучающих культурное и цивилизационное своеобразие русского народа: Н.А. Бердяева, С.Н. Булгакова, И.А. Ильина, В.С. Соловьёва, П.А. Сорокина, П.А. Флоренского, А.С. Хомякова и других.

Н.А. Бердяев не употреблял понятие «менталитет», но зато ввел ряд других близких к нему понятий, позволяющих выявить, прежде всего духовный облик русского на- рода. Это понятия «русский характер», «национальный тип», «слой русской души».

При этом философ выделяет два фактора, которые определили эти особенности русских людей, близкие к понятию «менталитет»: географический фактор и особенности религиозности. Первый фактор заключается в наличии огромного пространства, занимаемого российским суперэтносом, которое во многом определило широту и противоречивость русского национального характера, не связанного какими-либо территориальными ограничениями. На этот же фактор становления русского характера указывали А.С. Хомяков и В.С. Соловьев.

В исследованиях, так или иначе, связанных с изучением менталитета особое место принадлежит русскому философу И.А. Ильину, который занял критическую позицию по отношению к самой возможности изучения менталитета народа, который он оценивал как «коллективное бессознательное», которого в реальности, по его мнению, нет. В качестве аргумента в пользу этой точки зрения философ утверждал, что реальные духовные процессы, в конечном счете, принадлежат преимущественно отдельной личности и предполагают необходимость продолжительного уединения, способствующего духовному созреванию. Неверие И.А. Ильина в возможность реального существования менталитета народа как выражения его коллективных бессознательных состояний в то же время позволило наметить перспективы духовного развития личности, которая в своем индивидуальном существовании может отражать национальнокультурные особенности целого народа. Это происходит чаще всего в существовании выдающихся личностей, выражающих наиболее характерные особенности своего народа или этноса.

Свой вклад в изучение менталитета внесла тартуская школа семиотики в лице Ю.М. Лотмана, Вяч. Иванова, Б.А. Успенского, В.Н. Топорова. Предлагалось формировать понятие «менталитет» как порождение семиотической деятельности, представленной в соответствующих «культурных текстах». Тем самым это понятие рассматривалось как сугубо знаковое, искусственное образование, которое фиксирует те или иные процессы коммуникации и знаковые обозначения, формирующие психологическую реальность, оказывающие воздействие на массовую психологию народов.

Новый аспект в изучение менталитета внес выдающийся исследователь М.М. Бахтин, изучавший феномен народной «смеховой культуры», позволил существенно расширить границы этого понятия, включая в него представления о «телесности» как составной части проявляемого народного самосознания, особенно в процессе карнавального празднования.

В постсоветский период российские ученые стали 
уделять повышенное внимание менталитету советского народа, вызванное общественной потребностью осознания необходимости преемственности отечественной культуры и творческого переосмысления духовных традиций народов России. Среди ученых, изучающих эту тему, можно выделить Р. Бистрицкаса, Р. Кочюнаса, Л.Я. Гозмана, А.М. Эткинда, В.Е. Кагана, Б.И. Кочубея, А.А. Зиновьева. Уникальность советской цивилизации состояла в том, что ментальность народа искусственно формировалась соответствующей государственной политикой. Таким образом, появилась возможность изучения формирования новой ментальности сугубо политическими средствами, которыми располагало государство. Советский эксперимент показал наличие в том или ином менталитете как стихийных, так и конструируемых элементов, что позволяет оценивать этот феномен как «естественно-искусственное» образование. Искусственный элемент в формируемой ментальности советского общества был особенно значим, но не означает его отсутствия в условиях, когда эта искусственность носит завуалированный характер в обществах, демонстрируемых свою демократичность и плюрализм в политической жизни.

Особое место в изучении понятия «менталитет» принадлежит известному философу и литературоведу Г.Д. Гачеву, предложившему новое его видение, основанное на глубокое «погружение» в соответствующую культуру во всем ее разнообразии, определяя свой подход следующим образом: «Всякая национальная целостность есть Космо-Психо-Логос, то есть единство национальной природы, склада психики и мышления». [1]

\section{Обсужмение}

Понятие «менталитет» при всей его многозначности широко используется при изучении культур различных народов, этносов, стран. При всей широте трактовок этого понятия можно выделить некоторые, наиболее существенные аспекты его содержания. Необходимо признать, что определение понятия «менталитет» зависит от характера соответствующих исследовательских задач и социальной позиции исследователя. Так, например, с позиций «евроцентризма» это будет одно содержание понятия, с позиций глобализма - другое и т.д.

В последнее время все большее внимания уделяется так называемому «ментальному фону» той или иной эпохи и отдельных стран, а также складыванию национальных характеров и национальных культур, изучаемых этнологами и этнопсихологами. Понятие «менталитет» также осваивается в различных гендерных исследованиях.

Обращение современных исследователей к различным «историям ментальностей» позволило объединить в изучении культур самые различные гуманитарные дисциплины - историю, этнологию, лингвистику, культурологию, социологию, философию, семиотику, литературоведение, географию, экологию и пр.

\section{Зак^ючение}

Имеет смысл привести основные подходы к определению менталитета, представленные в научных дисциплинах, которые одновременно имеют всеобщее значение для исследований ментальных структур того или иного народа, этноса, общности. Так, в социальной психологии ментальность связывается со специфическими особенностями психики иногда целых народов, фиксируемая как «национальный характер», «народный дух», единство осознаваемых и неосознаваемых ценностных установок и норм, которые присутствуют у той или иной социальной группы, общности.

Этнологи рассматривают менталитет как совокупность представлений о приоритетах и нормативных аспектах социального поведения, которое обусловлено соответствующими социокультурными факторами, бессознательными установками как продукта соответствующей системы воспитания, социальной средой и т.д.

Культурологи, как правило, акцентируют свое внимание на духовных аспектах менталитета, включая особенности языка, мировоззрения, мировосприятия, самосознания. При этом отмечается, что «Менталитет функционирует в тесном сопряжении с культурой. Вместе с тем он не может рассматриваться как элемент культуры, поскольку не объективируется в привычных культурологических рамках. Менталитет может рассматриваться как функциональная глубинно-духовная основа ценностей культуры данного конкретного общества, как операциональная компонента культуры». [15, с.338].

Философы рассматривают менталитет как проявление преимущественно наивных представлений о мире, позволяющих воспринимать окружающую действительность целостно, как правило, оформленную в эстетических категориях. Причем место логики здесь заменяется определенными культурными архетипами.

Суммируя различные подходы в определении менталитета можно сделать вывод о том, что он представляет собой наличие целостной картины мира с соответствующими ценностными основаниями, которая существует продолжительное время и прямо не зависит от тех или иных экономических и политических факторов. Зато важными являются этнические предрасположенности, культурные традиции, проявляемые в особенностях мирочувствования, типа рациональности, языке, системах воспитания в качестве органичного элемента народной культуры в условиях определенного пространства, «обжитого» тем или народом, этносом, общностью. 


\section{ЛИТЕРАТУРА}

1. Гачев Г.Г. Национальные образы мира. Космо-Психо-Логос. - М., 1995.

2. Геродот История - М., изд-во «Азбука», 2019, 768 с.

3. Гуревич А.Я. Исторический синтез и школа «Анналов», М.: Индрик, 1993. 328с.

4. Ежова Е.А. К проблеме формулирования дефиниции «менталитет» и «ментальность» в этнопсихологической литературе», 2013 file:///D:/Downloads/5604-Article\%20Text-11204-1-10-20160707.pdf

5. Кассирер Э. Опыт о человек. Введение в философию человеческой культуры.

6. Лацарус, Мориц // Энциклопедический словарь Брокгауза и Ефрона : в 86 т. (82 т. и 4 доп.). — СПб., 1890-1907.

7. Леви-Брюль, Люсьен Сверхъестественное и природа в первобытном мышлении. - М., М.: Педагогика-Пресс, 1994. — 608 с. — (Серия: «Психология: Классические труды»)

8. Леви-Брюль, Люсьен Первобытное мышление. Коллективные представления в сознании первобытных людей и их мистический характер. - Изд-во «Красанд», 2014, 342с.

9. Ле ГоффЖ. Ментальности: двусмысленная история // История ментальностей и историческая антропология: Зарубежные исследования в обзорах и рефератах. М., 1996

10. Лосев А. Ф. Проблема символа и реалистическое искусство.— - 2-е изд., испр.—- М.: Искусство, 1995.—320 с. ISBN 5-210-02247-1

11. Монтескье Ш. «0 духе законов» Электронная библиотека «Гражданское общество». URL: http://www.civisbook.ru/

12. Николай Бердяев Душа России (сборник) ЗАО «Издательство Центрполиграф», 2016 Оригинал доступен на сайте КнигоГид https://knigogid.ru/books/760025-dusha-rossii/toread

13. Лосев А.Ф. Символ и художественное творчество. - Известия АН СССР. Отделение литературы и языка. - Т. ХХХ. Вып. 1. - М., 1971. - С. 3-13

14. Лотман Ю.М. Символ в системе культуры. Лотман Ю.М. Избранные статьи. Т. 1. - Таллинн, 1992. - С. 191-199

15. Полежаев Д.В. Идея менталитета в русской философии «золотого века» - Волгоград: Изд-во ВолГУ, 2003. - 360с.

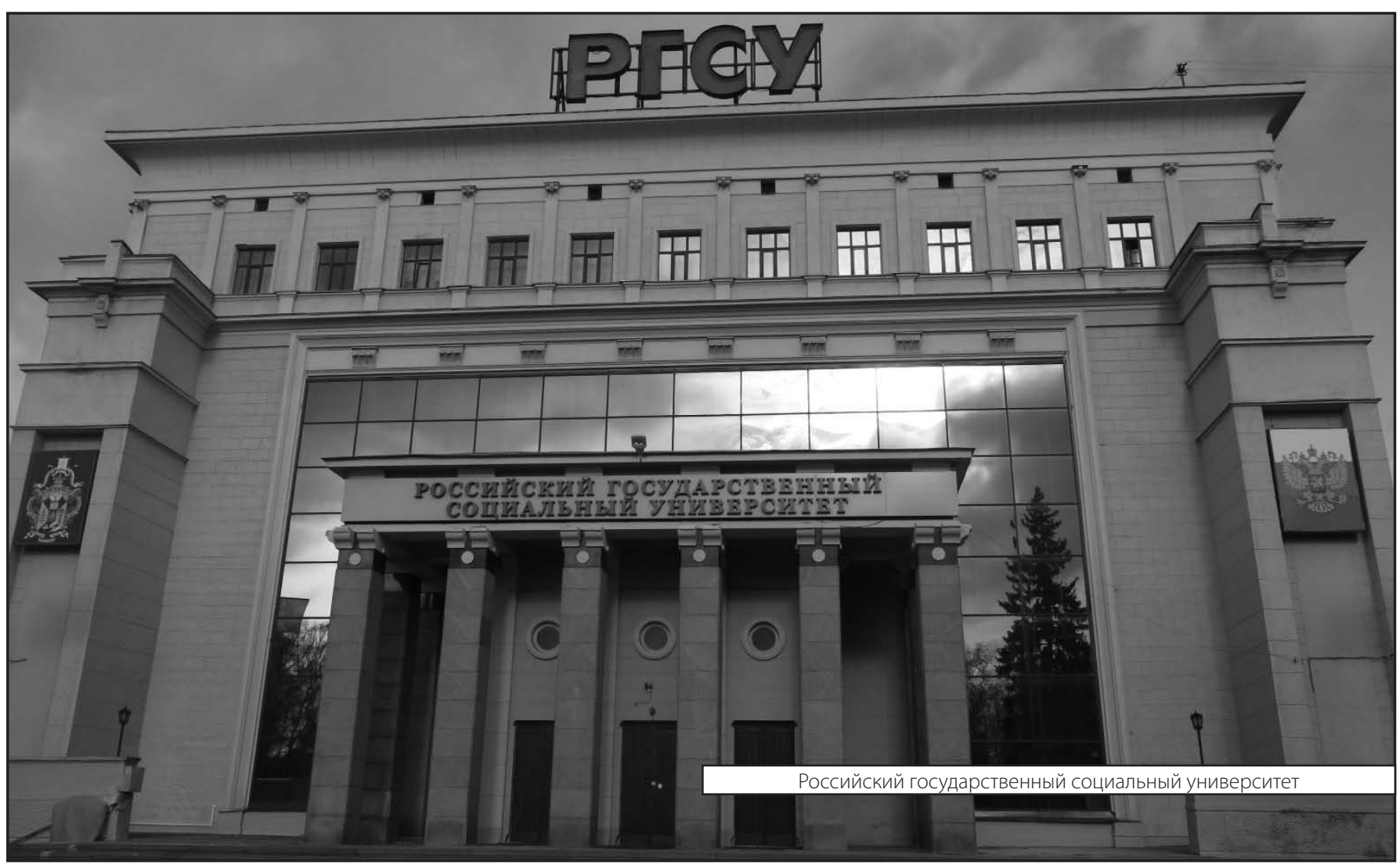

